\title{
Editorials
}

\section{Ave atque vale}

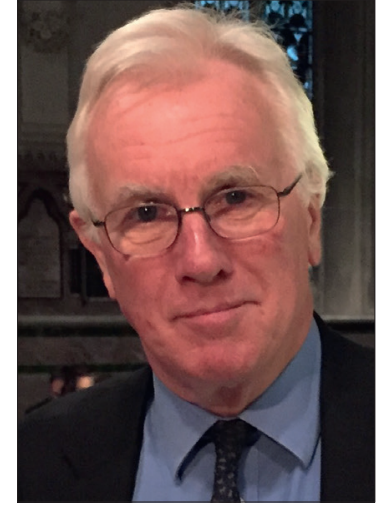

In almost 10 years in the BJGP editorial chair l've looked at over 5000 research and academic papers, and published getting on for 1000 of them. I thought it might be helpful to reflect on research and publication in general practice and primary care, as well as taking this opportunity to say some thank yous.

\section{IMPACT}

I'm leaving the BJGP at the end of March, and I'm delighted to be doing so at a time when the Journal, and its sister, BJGP Open, are in such good shape. The BJGP's Impact Factor, a measure of the frequency with which articles are cited by other peer reviewed publications, is 4.434 . This may not mean much to many readers, but, believe me, this is the metric which keeps journal editors awake at night. In truth, it probably shouldn't, because new and more relevant measures of impact are being devised, but for the time being it matters. The BJGP's impact factor is the highest of all primary care journals globally, and this wide relevance is reflected in the numbers of digital visits and downloads on the $B J G P$ website, running into the millions each year.

\section{RELEVANCE}

Readership surveys conducted by the RCGP indicate that the Journal is highly regarded as a major benefit of membership and

\section{the quality, as well as the quantity, of primary care research continues to increase.}

fellowship, although there is a continuing and lively debate about the extent to which it meets the needs of clinicians who are not engaged in research or teaching, reflects or reports on College policy, is too international or not eclectic enough, or contains too many or too few non-clinical articles. The College produces and publishes so much excellent material that, if it was better coordinated, the needs of all its members could be satisfied. Synthesising and crossreferencing material published in the $B J G P$, BJGP Open, InnovAiT, the e-learning and CPD programmes, and other publications, such as Council and policy papers, could create a powerful resource. The BJGP is also crucially important to the UK's academic primary care community for publication and dissemination of research.

\section{PEER REVIEW}

We take our relationships with our authors and reviewers very seriously. We do our best to provide informed and constructive decisions on submissions as quickly as possible, and at present the median time to a first decision after submission of a research paper is only 11 days. The link with BJGP Open provides an alternative venue for research that doesn't quite cut the mustard at the BJGP. The quality of reviews is often such that authors of papers we decline are able to redraft much better papers for submission to other journals. Peer reviewers are the unsung heroes of academic publishing, and this is my opportunity to say an enormous thank you to all our reviewers for the care, consideration, and diligence that you show in providing advice to me and to our authors. Peer review has been under enemy fire for years, although a convincing alternative

\section{"Peer review has been under enemy fire for years, although a convincing alternative has never been established."}

has never been established. I don't think that BJGP authors, who often comment favourably on our submission and review processes, would take issue with a peer review system that succeeds in being both critical and formative. We provide guidance and feedback to our reviewers on the quality of their reviews. We have decided to accept, for a trial period, Registered Reports of clinical trials. This is a new publishing format, in which the research question and methodology are peer reviewed before data collection begins.

\section{RESEARCH QUALITY}

My impression overall is that the quality, as well as the quantity, of primary care research continues to increase. Experimental methods, such as randomised controlled trials, are more frequently represented among submissions, health services research evaluations are more sophisticated, and research using large databases is increasingly valuable and penetrating. The clinical strengths of primary care research at present lie in the fields of cancer, cardiovascular disease, mental health, infectious diseases, and comorbidity. Strong cross-cutting themes include the measurement and communication of risk, the organisation of care, with a welcome current emphasis on continuity, the use of new technologies in communication and diagnosis, the workforce and recruitment crisis facing the profession, and the importance of teaching and role modelling in general practice. The mantra 'is it new and is it true?' still holds good as a selection criterion, along with timeliness, relevance, and impact/ importance to clinical practice. As we use social media more and more to promote and disseminate research publications, wider societal relevance and likely media interest inevitably creep in to editorial decision making.

\section{RESEARCH QUESTIONS}

There is always room for improvement. Researchers need to be sure that they 
have read and acknowledged the research literature preceding their study and leading to their own research question. Some papers seem to have been written without much regard to the existing literature and can turn out to be restatements of what is already known. Some qualitative research is in danger of falling into this category, sometimes with non-clinical researchers simply reframing issues that are familiar, often second nature, to GPs. Articles that are overcritical of behaviour or knowledge and skills, particularly when written without a GP co-author, can be problematic. Measuring research against the 'Who cares? and So-what?' tests is still useful: studies can be immaculately conducted but of little interest. The BJGP encourages authors to write a crisp, nondiscursive final section, 'Implications for research and practice'. Inability to deliver a focused paragraph here is often indicative of an unfocused research question in the first place. Questions about likely interest, scope, and format can often most easily be resolved by an informal approach to the Editor. We are very interested in the climate/ sustainability implications of primary care research and publishing, and are open to ideas for publications in this area.

\section{HEALTH SERVICES RESEARCH AND MEDICAL EDUCATION RESEARCH}

Two subject areas that can be particularly challenging are medical education research and health services research. Because of the relatively low priority given to funding medical education research - short-sightedly - single-institution, small-scale projects are often reported, leading to problems of generalisability and applicability. There is a need for greater clarity about the relative roles of sharing good practice, and of conducting and publishing formal research evaluations. In health services research the reverse is, paradoxically, true: large-scale research evaluations of health services innovations using traditional trial methodology can be so expensive and cumbersome that the research question has ceased to matter by the time the trial reports. Finding better ways of sharing and taking up good practice, which do not require such large investments of time and money, particularly in a fast-changing health service, must be a priority.

\section{OPEN ACCESS}

The BJGP is a hybrid open access journal, which means that authors can choose to pay a fee for their work to be made immediately accessible and not hidden behind a subscription paywall, or they can choose not to do this. Over one-third of our published papers are open access. An international initiative known as 'Plan $S$ ' has proposed that all research funded by national research institutions must be published in full open access journals. Open access does not mean that standards for acceptance are lower, but that barriers to full availability of research are removed: in the future world of full open access, the costs of research publication will be borne by funders, and research journal subscriptions will be a thing of the past. Open access costs may cause problems for researchers working outside mainstream institutions and the UK. We are in a transitional phase of policy development at present, but it is likely that the move towards full open access has enough momentum to carry most journals in that direction in the next few years.

\section{SOMETHING COMPLETELY DIFFERENT}

The BJGP, like general practice itself, contains something for everyone. We are very proud of the Life \& Times section, which is designed to be a stimulating and eclectic mix of opinion, personal experience, reflections on key events and individuals that have shaped general practice, reviews and appreciations of the arts, and the simply quirky. We have been extremely fortunate to have a loyal group of regular columnists, and are enormously grateful to Des Spence, Tim Senior, Saul Miller, and Ahmed Rashid for their excellent work, supplemented from time to time by John Frey's letters from America, which make me feel very grateful to be working in the UK. We welcome good writing of all kinds, and hope that you will

\section{ADDRESS FOR CORRESPONDENCE}

Roger Jones

Editor, BJGP

Email: roger.jonesवkcl.ac.uk

think about submitting your own ideas, thoughts and experiences to the Journal.

Keeping a monthly publication topical is a particular challenge, and although we keep editorial and debate slots open for as long as possible, it's difficult to keep up with every controversy facing general practice. As well as featuring some of these on the Journal homepage, we also welcome contributions to BJGP Life, our blog, where we are able to post articles almost immediately, to ensure timeliness. Please think of using this medium as a way of getting your messages and arguments across to your colleagues.

\section{THANK YOU}

The BJGP is published by the RCGP, and most of the Journal team work at 30 Euston Square. The Journal is editorially independent of the College and is guided by an Editorial Board of clinicians and medical scientists. My thanks go to the College and to the Board for their strong support over the years. The BJGP's Deputy Editor, Euan Lawson, has created a brilliant Journal section in Life \& Times, and a very fine blog at BJGP Life. He also conceived and delivered BJGP Open. Huge thanks to him and to all of the BJGP and BJGP Open staff: Catharine, Haji, Erika, Amanda, Indy, Simone, Tony, Moira, Tom, Margaret, and Mona.

\section{WELCOME!}

Finally, a very warm welcome to Dr Domhnall MacAuley, who takes up the BJGP Editorship in April. Domhnall has a distinguished medical editing $\mathrm{CV}$ and will bring new energy and ideas to the next chapter of the BJGP story. I'll miss our little empire on the fourth floor of 30 Euston Square. Best wishes and good luck to all of you.

\section{Roger Jones}

Editor, BJGP

\section{Provenance}

Freely submitted; not externally peer reviewed.

DOI: https://doi.org/10.3399/bjgp20X708305 